\title{
Effect of Enterococcus faecalis pyelonephritis on the intracortical accumulation kinetics of gentamicin in rats
}

\author{
Martial Jullien, Guy Thériault, BSc, Michel G Bergeron, MD, frCPC, Denis Beauchamp, PhD
}

\begin{abstract}
The role of serum levels on the intracortical accumulation kinetics of gentamicin was evaluated in normal and Enterococcus faecalis-infected kidneys using a short term infusion model in conscious rats. Female Sprague-Dawley rats were infused over a period of $6 \mathrm{~h}$ with gentamicin achieving individual steady-state serum levels ranging from 0.5 to $20 \mu \mathrm{g} / \mathrm{mL}$. Pyelonephritis was induced by a direct inoculation of the left kidney with a suspension of $E$ faecalis. This model resulted in severe infection of the left kidney and mild infection of the right kidney. Gentamicin cortical concentrations were analyzed as a function of serum levels by linear regression (least squares regression analysis).
\end{abstract}

Steady-state elevation of serum concentrations of gentamicin was associated with a linear increase of cortical concentrations in normal, and in both left and right infected kidneys. No significant difference in the kinetics of gentamicin uptake was observed between normal and right and left infected kidneys. Therefore, $E$ faecalis pyelonephritis does not modify the intracortical accumulation kinetics of gentamicin. Can J Infect Dis 1990;1(4):117-120

Key Words: Enterococcus faecalis, Gentamicin intracortical uptake, Pyelonephritis

were more severe than those observed in kidneys infected with Enterococcus faecalis (8). There has been speculation that endotoxin might have been responsible for the disturbed intrarenal distribution of aminoglycoside in $E$ coli pyelonephritis. In fact, Bergeron and Bergeron (9) showed that endotoxin increases the level of aminoglycoside in the renal parenchyma compared to normal, while the tissue levels of cephalothin were not modified.

More recently, Beauchamp et al (10) showed that the intracortical accumulation kinetics of gentamicin was modified in the presence of $E$ coli pyelonephritis. The aim of the present study was to evaluate the effect of $E$ faecalis pyelonephritis on the intracortical accumulation kinetics of gentamicin using a short term infusion model in conscious rats.

\section{MATERIALS AND METHODS}

Handling of animals and treatment: Female Sprague-Dawley rats (Charles River Breeding Laboratories Inc, Montreal) weighing between 195 
and $265 \mathrm{~g}$ were used. They had free access to food and water throughout the experiment. Two groups of animals were studied: normal $(\mathrm{n}=22)$ and pyelonephritic $(n=23)$ rats. Pyelonephritis was induced four days before perfusion. Animals were anesthetized with $350 \mathrm{mg} / \mathrm{kg}$ chloral hydrate, and their left sides were shaved. An incision was made at the level of the left kidney and the kidney was exposed and injected with $0.1 \mathrm{~mL}$ of an inoculum containing $10^{7}$ to $10^{8} \mathrm{E}$ faecalis (ATCC 23241). The gentamicin minimal inhibitory and minimal bactericidal concentrations for the strain were 32 and $128 \mu \mathrm{g} / \mathrm{mL}$, respectively. The suspension was injected directly into the medulla through the upper and lower poles of the kidney, as described by Kaye (11). This inoculation produces two kinds of infection: a serious pyelonephritis of the left kidney and a less severe infection of the right kidney due to the reflux of infected urine into the right ureter and kidney, rats being naturally prone to vesicoureteral reflux.

The day before the infusion, normal and infected animals were anesthetized with intraperitoneal chloral hydrate $350 \mathrm{mg} / \mathrm{kg}$. A polyethylene catheter (PE-50; Intramedic, New Jersey), prefilled with $25 \mathrm{U} / \mathrm{mL}$ heparin was inserted into the right jugular vein. The other end of the catheter was guided subcutaneously until it emerged through a hole made through the skin of the neck, and was secured. After recovering from anesthesia, rats were returned to their cages and left undisturbed overnight with free access to food and water.

The infusion was started on the following day by injection of a loading dose of gentamicin through the catheter in order to obtain the required serum levels instantaneously. Catheters were then connected to $20 \mathrm{~mL}$ syringes containing the appropriate solution and mounted in a continuous flow perfusion pump (Harvard apparatus; Ealing Scientific Ltd). The rate of perfusion was $0.02 \mathrm{~mL} / \mathrm{min}$. Gentamicin concentrations in the loading (LD) and infusion (ID) doses were adjusted to the body weight of each animal and calculated from the serum half-life, the elimination constant $(\mathrm{Kel})$ and the apparent volume of distribution $\left(\mathrm{V}_{\mathrm{d}}\right)$ previously determined in the authors' laboratory where $\mathrm{LD}=$ expected serum levels $\times \mathrm{V}_{\mathrm{d}}$; and $\mathrm{ID}=$ $(\mathrm{LD} \times \mathrm{Kel}) /$ rate of infusion $(10,12)$.

Blood samples were drawn from the catheter after $3 \mathrm{~h}$ of perfusion. Exactly $6 \mathrm{~h}$ after the beginning of the infusion the animals were killed by decapitation and bled. Blood was centrifuged at $1000 \mathrm{~g}$ for 15 mins and the serum was immediately frozen $\left(-20^{\circ} \mathrm{C}\right)$ for further antibiotic determinations. The right kidney of the normal and the right and the left kidneys of the infected rats were rapidly removed and bisected. The cortex of each kidney was dissected and immediately frozen for further antibiotic assays.

Gentamicin assay: The renal cortical accumulation of gentamicin was measured by a fluorescence polarized immunoassay (TDX System; Abbott Laboratories, Illinois). Briefly, samples of kidney cortex were homogenized in TDX dilution buffer with a Tissue-Tearor (Biospec Products, Oklahoma).

The homogenates were sonicated with a sonicator (model 375; Bionetics Ltd) and diluted in TDX dilution buffer to obtain concentrations between 0 and $10 \mu \mathrm{g} / \mathrm{mL}$. Standards were prepared in blank cortex homogenates at the same tissue dilution as that used for tissue assays. The recovery of gentamicin in renal homogenate was $87.7 \pm 1.2 \%$ (mean \pm standard deviation).

Renal function: Creatinine clearance was evaluated before the experiment in eight normal and eight infected rats. Briefly, normal and infected animals (three days following induction of infection) were individually placed in metabolic cages so that urine could be collected over $24 \mathrm{~h}$. Animals were then killed and bled, and the serum was collected. Creatinine levels were measured in urine and serum for evaluation of creatinine clearance.

Results analysis: Since the relationship between renal cortical concentrations of gentamicin and the time of infusion was linear (13), cortical gentamicin concentrations were transformed in the renal cortical accumulation rate $(\mu \mathrm{g} / \mathrm{g} / \mathrm{h})$. The renal cortical gentamicin accumulation rate was analyzed as a function of serum levels by linear regression (least squares regression analysis). Animals that showed a difference of more than 30\% between serum levels measured after $3 \mathrm{~h}$ compared to serum levels measured at $6 \mathrm{~h}$, were eliminated.

Statistics: Comparisons between curves were done using the method described by Snedecor (14).

\section{RESULTS}

Renal function: Creatinine clearance was not significantly different between infected and normal rats (four days following induction of infection). On day 4, diuresis was significantly higher in the infected animals compared to the control group: $18.5 \pm 7.5$ and $7.9 \pm 4.1 \mathrm{~mL} / 24 \mathrm{~h}$, respectively $(\mathrm{P}=0.002)$. Water intake was also higher in the infected rats compared to the normal animals: $32 \pm 6$ and $13 \pm 9 \mathrm{~mL} / 24 \mathrm{~h}$, respectively $(\mathrm{P}=0.0002)$. Steady-state serum levels: The serum levels of gentamicin measured in normal and infected rats after 3 and $6 \mathrm{~h}$ of infusion remained constant. The correlation between concentrations measured at 3 and $6 \mathrm{~h}$ over the whole range of serum levels for 


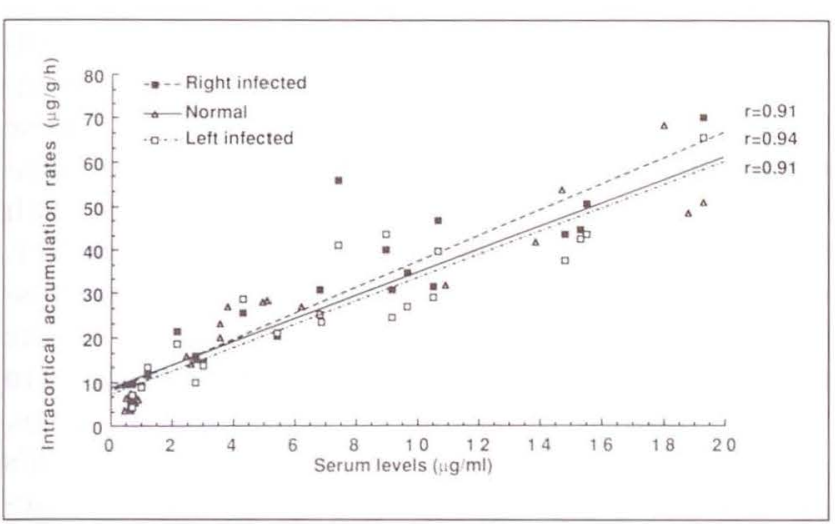

Figure 1) Intrarenal accumulation kinetics of gentamicin in normal and Enterococcus faecalis-infected kidneys. Relationship between steady-state serum concentrations and renal cortical accumulation rates of gentamicin. Gentamicin was infused over $6 \mathrm{~h}$ achieving individual steady-state serum levels

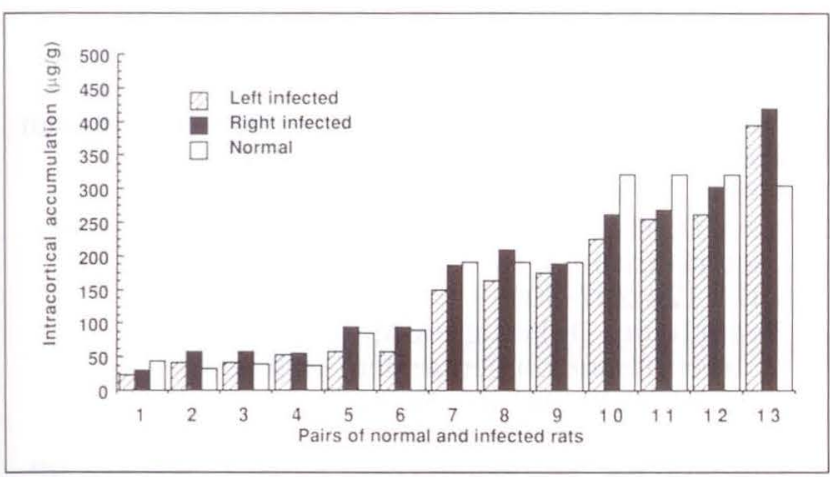

Figure 2) Comparison between the intracortical accumulation of gentamicin measured in normal and right and left infected kidneys. Normal and infected animals were paired on the basis of body weight and steady-state serum levels (not more than 20\% variation for each parameter between normal and infected rats)

normal animals was $(x=3 h, y=6 h): y=-0.27$ $+1.18 \mathrm{x} ; \mathrm{r}=0.97 ; \mathrm{n}=22$. The correlation for infected animals was $\mathrm{y}=0.71+0.95 \mathrm{x} ; \mathrm{r}=0.93 ; \mathrm{n}=23$.

Intracortical accumulation kinetics: Steadystate elevation of serum concentrations (S) of gentamicin was associated with a linear increase of cortical accumulation rate (V) in normal and in right and left infected kidneys (Figure 1). The linear regression and slope of these three curves were not significantly different: normal kidneys $\mathrm{V}=2.65 \mathrm{~S}+8.19, \mathrm{r}=0.94, \mathrm{n}=22$; right infected kidneys $\mathrm{V}=2.93 \mathrm{~S}+8.00, \mathrm{r}=0.91, \mathrm{n}=23$; left infected kidneys $\mathrm{V}=2.66 \mathrm{~S}+6.87, \mathrm{r}=0.91, \mathrm{n}=23$.

Intracortical accumulation: The correlation between gentamicin concentrations measured in right (R) and left (L) infected kidneys over the whole range of serum levels was: $\mathrm{L}=0.34+0.87 \mathrm{R}, \mathrm{r}=0.98$, $\mathrm{n}=23$. No significant difference was observed between the accumulation of gentamicin in right and left infected kidneys.
The intracortical accumulation of gentamicin measured in the normal kidneys was compared to the same in right and left infected kidneys (Figure 2). Pair comparisons were done between normal and infected rats of similar weight and steadystate serum levels during the infusion (not more than $20 \%$ variation for each parameter). No significant difference was observed in the accumulation of gentamicin between normal and both right and left infected kidneys.

\section{DISCUSSION}

The intracortical accumulation kinetics of gentamicin were evaluated in normal and $E$ faecalisinfected kidneys. This study shows that the intracortical uptake and kinetics of gentamicin were not modified in the presence of infection. The accumulation kinetics of gentamicin were linear as steady-state serum levels varied from 0.5 to 20 $\mu \mathrm{g} / \mathrm{mL}$.

The influence of renal infection on the intrarenal distribution of different antibiotics is quite variable. Tetracycline pharmacokinetics were not affected in the presence of $E$ faecalis pyelonephritis, but intrarenal levels were found to be lower in animals suffering from Gram-negative infection (15). Moreover, it has been observed previously that cortical and medullary levels of ampicillin, cephalothin and trimethoprim were lower in $E$ coli-infected kidneys compared to control tissue, while sulfamethoxazole levels were not affected by infection $(16,17)$. Bergeron et al $(7)$ and Beauchamp et al (8) have shown a greater uptake of gentamicin in $E$ coli-infected kidneys compared to normal kidneys. These changes observed in the presence of Gram-negative infection were more severe than those observed in kidneys infected with $E$ faecalis (8). Endotoxin or other bacterial products liberated during antibiotic therapy (18) might have been responsible for the increased accumulation of gentamicin in the infected kidneys $(6,7)$. A greater accumulation of gentamicin, netilmicin, tobramycin and amikacin, but not cephalothin, was observed in the renal cortex and medulla of endotoxin-treated animals than in the kidneys of normal animals $(9,19)$.

The present study used a model of short term infusion in order to ensure that the intracortical uptake of aminoglycoside was not disturbed by the cellular necrosis and post necrotic regeneration usually observed during conventional therapy (20). The linear uptake of gentamicin observed in normal kidneys has also been reported earlier over the same range of serum levels $(10,13,21)$. Present results corroborate these studies.

Previous studies done in the authors' laboratory showed that $E$ coli renal infection modified 
both the intracortical accumulation and the kinetics of gentamicin uptake (10). It is thus clear that the kinetics of uptake of gentamicin behaves differently in $E$ coli than in $E$ faecalis pyelonephritis. These results are in accordance with previous studies which showed that the intrarenal distribution of gentamicin was more severely disturbed in E coli pyelonephritis than in E faecalis infection. The role of endotoxin on the intracortical uptake of gentamicin was investigated using the same model of short term infusion. Tardif et al (21) showed that endotoxin modified the intracortical accumulation kinetics of gentamicin, as previously observed in E coli pyelonephritis (10).

In the present study, the total accumulation of

ACKNOWLEDGEMENTS: This study was supported by the Kidney Foundation of Canada. Denis Beauchamp is a scholar of the PMAC Health Research Foundation. Martial Jullien was a foreign medical student from France who trained in our laboratory. We thank Pierre Provencher for statistical analysis and Lise Villeneuve for secretarial help. The gentamicin was kindly donated by Schering Canada Inc.

\section{REFERENCES}

1. Bennett WM, Hartnett MN, Craven R, Gilbert D, Porter GA. Gentamicin concentrations in blood, urine, and renal tissue of patients with end-stage renal disease. J Lab Clin Med 1977;90:389-93.

2. Riviere JE, Copper GL, Hinsman EJ, Carlton WW. Gentamicin pharmacokinetic changes in induced acute canine nephrotoxic glomerulonephritis. Antimicrob Agents Chemother 1981;20:387-92.

3. Chiu PJS, Long JF. Urinary excretion and tissue accumulation of gentamicin and para-aminohippurate in post-ischemic rat kidneys. Kidney Int 1979;15:618-23.

4. Lecompte J, Dumont L, Hill J, Sovich P, Lelorier J. Effect of water deprivation and rehydration on gentamicin disposition in the rat. J Pharmacol Exp Ther 1981;218:231-6.

5. Teixeria RB, Kelley J, Albert H, Pardo V, Vaamonde CA. Complete protection from gentamicin-induced acute renal failure in the diabetes mellitus in rat. Kidney Int 1982;21:600-12.

6. Bergeron MG, Trottier S, Lessard C, Beauchamp D, Gagnon PM. Disturbed intrarenal distribution of gentamicin in experimental pyelonephritis due to Escherichia coli. J Infect Dis 1982;146:436-9.

7. Beauchamp D, Poirier A, Bergeron MG. Increased nephrotoxicity of gentamicin in pyelonephritic rats. Kidney Int 1985;28:106-13.

8. Auclair P, Lessard C, Bergeron MG. Renal pharmacokinetic changes of gentamicin during enterococcal pyelonephritis. Antimicrob Agents Chemother 1988;32:736-9.

9. Bergeron MG, Bergeron Y. Influence of endotoxin gentamicin measured in normal kidneys was compared to that in infected kidneys of animals infused at similar steady-state serum levels. These data show that the tissue accumulation of gentamicin can be predicted from serum levels in both normal and $E$ faecalis-infected kidneys. However, one cannot exclude the possibility that $E$ faecalisinfected kidneys might be more susceptible to the nephrotoxic potential of gentamicin compared to normal kidneys at similar cortical levels of drugs.

The authors conclude, therefore, that $E$ faecalis pyelonephritis does not modify gentamicin accumulation kinetics and that serum levels are good predictors of gentamicin accumulation in the renal cortex in the presence of $E$ faecalis infections.

on the intrarenal distribution of gentamicin, tobramycin, amikacin, and cephalothin. Antimicrob Agents Chemother 1986;29:7-12.

10. Beauchamp D, Bouchard A, Theriault G, Pellerin M, Bergeron WG. Effect of E coli pyelonephritis on the intrarenal accumulation kinetics of gentamicin and netilmicin in rats. Clin Invest Med 1990; 13:145-51.

11. Kaye D. The effect of water diuresis on spread of bacteria through the urinary tract. J Infect Dis 1971;124:297-305.

12. Beauchamp D, Pettigrew M. Influence of hydrocortisone on gentamicin-induced nephrotoxicity in rats. Antimicrob Agents Chemother 1988;32:992-6.

13. Giuliano RA, Verpooten GA, Verbist L, Wedeen RP, De Broe ME. In vivo uptake kinetics of aminoglycosides in the kidney cortex of rats. J Pharmacol Exp Ther 1986;236:470-5.

14. Snedecor GW. Statistical Method Applied to Experiments in Agriculture and Biology. Ames: Iowa State College Press, 1956:394-412.

15. Romas NA, Clark L. The distribution of tetracycline in renal tissue during pyelonephritis. J Urol 1969;102:541-6.

16. Trottier S, Bergeron MG. Intrarenal concentrations of ampicillin in acute pyelonephritis. Antimicrob Agents Chemother 1981;19:761-5.

17. Bergeron MG. Therapeutic potential of high renal levels of aminoglycosides in pyelonephritis. J Antimicrob Chemother 1985; 15:4-8.

18. Goto H, Nakamura S. Liberation of endotoxin from Escherichia coli by addition of antibiotics. Jpn J Exp Med 1980;50:35-43.

19. Bergeron MG, Bergeron Y, Beauchamp D. Influence of hydrocortisone succinate on intrarenal accumulation of gentamicin in endotoxemic rats. Antimicrob Agents Chemother 1987;31:1816-21.

20. Laurent G, Maldague P, Carlier MB, Tulkens PM. Increased renal DNA synthesis in vivo after administration of low doses of gentamicin to rats. Antimicrob Agents Chemother 1983;24:586-93.

21. Tardif D, Beauchamp D, Bergeron MG. Influence of endotoxin on the intracortical accumulation kinetics of gentamicin in rats. Antimicrob Agents Chemother 1990;34:576-80. 


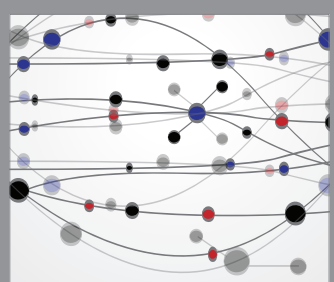

The Scientific World Journal
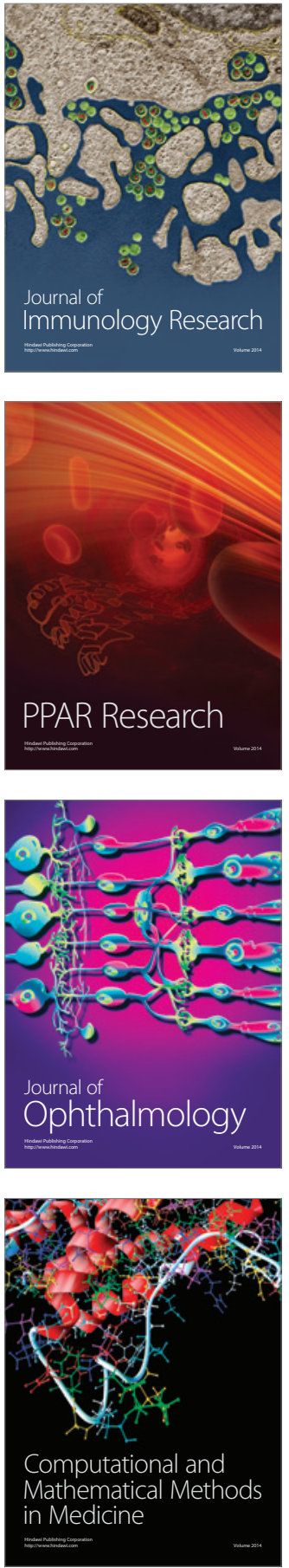

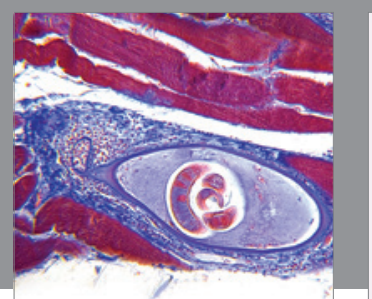

Gastroenterology Research and Practice

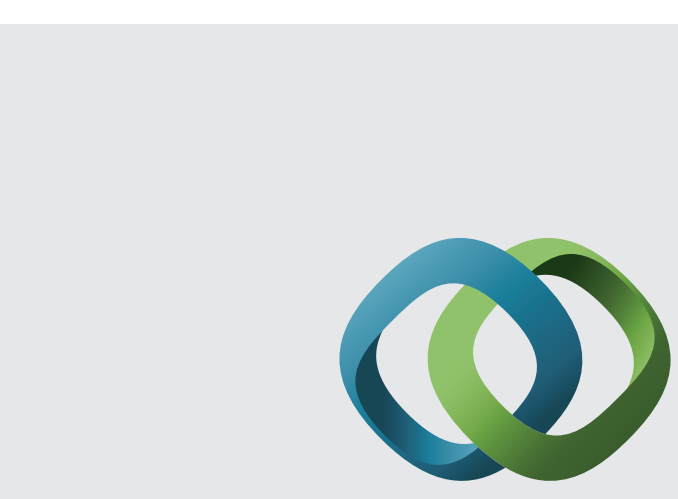

\section{Hindawi}

Submit your manuscripts at

http://www.hindawi.com
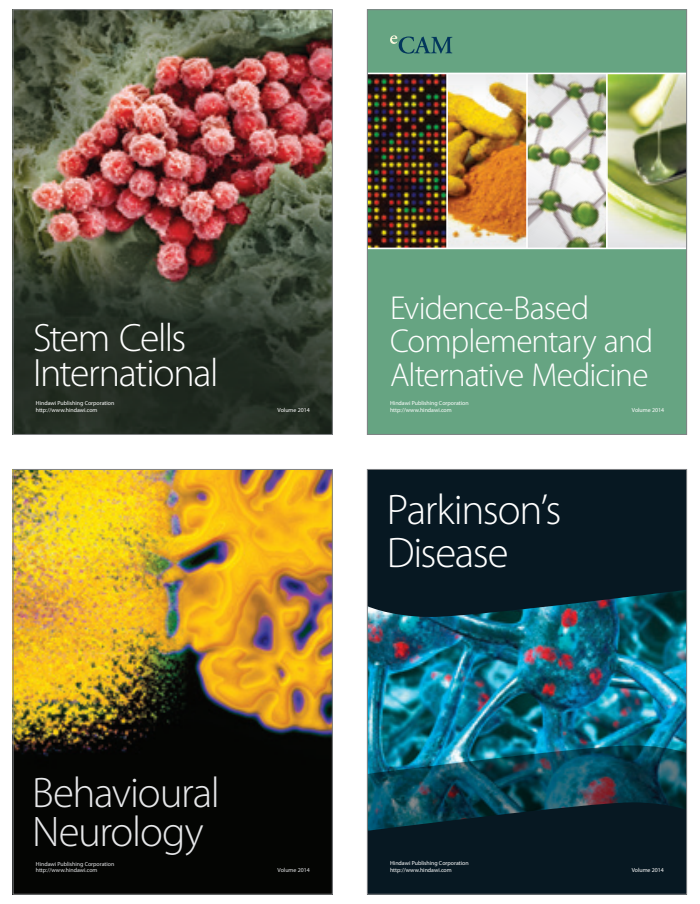
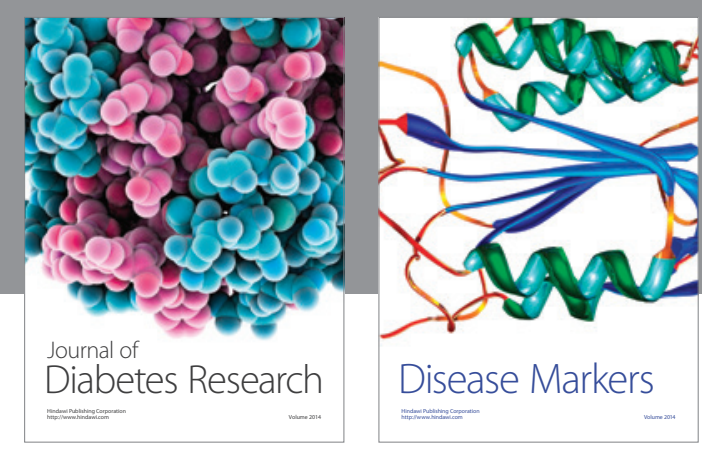

Disease Markers
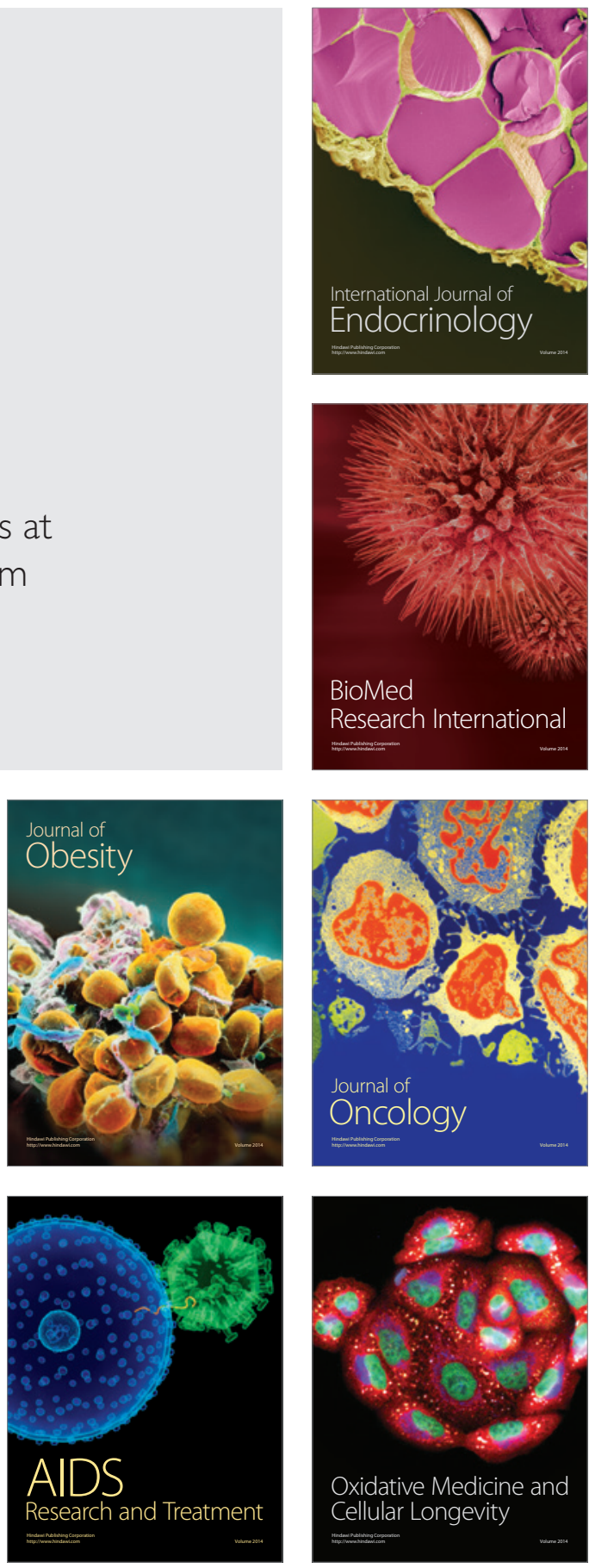